\title{
Unconventional Western System
}

National Cancer Institute

\section{Source}

National Cancer Institute. Unconventional Western System. NCI Thesaurus. Code C15890.

NIH: Subcategory of alternative medical systems in CAM. This sub-categ ory deals with alternative medical systems developed in the West that are not dealt with elsewhere. This includes systems such as homeopathy, Anthroposophically- extended Medicine, Environmental Medicine, Functional Medicine, Radionics, Cayce-based therapies, etc. Included are: Homeopathy, Environmental Medicine, Functional Medicine, Anthroposophically-extended medicine, Radionics, Radiesthesia, Psionic medicine, Caycebased systems. 